the operation of the equipment and most patients are very happy to "talk" to the machine. Reporting of $x$-rays and E.C.G's. is done on specially designed consoles directly by the consultant concerned. This facility has only been implemented recently but seems to work very smoothly.

The reasons for our success are perhaps threefold. Firstly, we opted for a system that was already operational and then took over a year in adapting it to our needs before installation occurred. Secondly, great emphasis has been put on staff training and the saving in paperwork has been obvious to all. Thirdly, we have used simple equipment and techniques where possible, rather than more complex ones. We feel that these principles could, with advantage, be followed in many commercial computer installations as well as medical ones.-We are, etc.,

H. B. WRIGHT. G. Pincherle.

B.U.P.A. Medical Centre,

\section{Wrong Operations}

SIR,-The recent correspondence on the subject of wrong operations initiated by Dr. P. H. Addison (22 August, p. 461) prompts me to bring to the attention of your readers a method of patient identification which is routinely practised in Sweden.

This is to include the patient's birth date as part of the identification document in the form of a six-figure number representing the year, month, and day of the patient's date of birth. For example, a patient born on 30 May 1919 would have the number 190530 preceding his name on all hospital documents.

According to my information this system has eliminated completely the error of the wrong patient being operated upon; additional advantages are that the patient can supply his own identification number on admission (unless he is unconscious) and, what is more important, any doctor or nurse attending a patient can verify his identity at any time merely by asking his date of birth. These points were clearly made by $\mathrm{Dr}$. T. Healey in a different context (1 August, p. 277), though the letter from $\mathrm{Mr}$. V. Biske (12 September, p. 647) is relevant here.

The universal adoption of this simple identification system into British hospitals could eliminate one cause of the wrong operation being performed; the only sure way of avoiding the "wrong side" type of error is to adhere rigidly to the routine described by Mr. A. G. Butters (26 September, p. 772).-I am, etc.,

\section{J. N. THORPE.}

Royal Hampshire County Hospital,

Winchester, Hants.

SIR,-It is certainly to be deplored that wrong operations should ever be carried out, and up to all concerned to see that their numbers are kept to the bare minimum. May I remind Mr. T. Keith Lyle (19 September, p. 711) that many operations have to be carried out as emergencies in the night on unronscious, uncooperative, disorientated, and deranged patients, where the set piece with all the accepted precautions is impossible. It is in this area that most of the danger lies-which adds to the wear and tear on all concerned in this type of surgery.

Incidentally, the public would be reassured and the perspective adjusted if somewhere in the propaganda campaign the number of wrong operations was expressed as a proportion of the total.-I am, etc.,

Accident Service,
Radcliffe Infirmary,
Oxford.

\section{Allegations of Negligence}

SIR,-Mr. J. Camp's letter (3 October, p. 51) concerning the incidence of allegations of negligence was interesting.

I would like to ask if such an allegation has ever been made against a pathologist? If not, is there not good reason for asking the protection societies to accept a lower premium to protect pathologists who, as far as I know, never remove the wrong fingers or legs, and never cause distress by leaving instruments in the abdomen-I am, etc.,

\section{Pathology Department, Western Infirmary,
Glasgow W.1.}

RICHARD CONNER.

\section{Living it up with Concorde}

SIR,-Your correspondent on time zone changes and supersonic flight ( 3 October, $p$. 53) concludes that safety in the air could be seriously compromised by the disturbed diurnal rhythm of aircrew. He has described the difficulties of the initial adaptation to a new time zone, but, though this is of particular interest to passengers, it is of less importance to aircrew as they are not required to live as the community during their short stay. The duty hours of aircrew are irregular and usually bear little relation to the normal working hours of successive localities, while their rest may be taken as required during their off-duty periods, and these latter last at least 24 hours if many time zones have been crossed.

Rapid time-zone changes superimposed upon irregular hours of duty lead to a complex work-rest schedule, and experienced aircrew modify their urgent needs for sleep, particularly after duty, in order to create an acceptable sleep pattern preceding the next flight. ${ }^{2}$ It is of interest that in a recent study of an airline pilot his total sleep over 72-hour periods preceding scheduled flights was not less than the minimum observed over any three days of non-flying duty. ${ }^{1}$

The predominant problem of aircrew operating worldwide east-west routes is to establish a rhythm of work and rest which provides satisfactory sleep. Aircrew have extensive experience of this problem, and your correspondent may rest assured that the duty hours of supersonic transport aircrew will be compatible with an accept- able sleep pattern and will in no way compromise the safety of the aircraft or of the passengers. - We are, etc.,

\section{Royal Air Force Institute of \\ A. N. Nicholson. \\ Aviation Medicine,
Farnborough, Hants. \\ F. S. Preston.} Air Corporations Joint Medical Service,
Hounslow, Middx. 1 Nicholson, A. N., Aerospace Medicine, 1970, 41,
626.
2 Preston, F. S., Transactions of the Society of
Occupational Medicine, 1970, 20, 77 .

\section{Accident and Emergency Services}

SIR,-May I comment on your leading article (10 October, p. 68) on the report of the working party of the Accident Services Review Committee.

With the emergence of "community medicine" in its general sense there cannot now be any doubt about the crucial role of the casualty surgeon who makes this work his wholetime interest. The report, however, makes only loose reference to a career structure, and implies that it would involve a long period of apprenticeship in the casualty department in a subconsultant capacity.

It cannot be emphasized enough that qualification for such a responsible post requires a first-hand knowledge of the treatment of emergencies in all specialties. As well as this, the casualty surgeon must be able to diagnose and assess future requirements in each specialty. Such experience can only be obtained by diverse training largely outside the department. Postgraduate training in the major disciplines of general medicine and surgery and orthopaedics would be a minimal preliminary, and concomitant experience in other specialties would need to be acquired. Such a vocation as "casualty" cannot any longer be considered as subsidiary and appointees would have to be of some seniority.

Who could do other than give to the casualty sister the $100 \%$ praise given in the report? She above all has a key position in the community. The executive on his way to committee who presents with a thumb "trapped in the car door" is hardly filled with the milk of human kindness, but sister has to deal considerately with the attendant social and administrative problems not of one such case but more than 30,000 year. We are all stimulated by the management of the odd emergency. Continuous charge is demanding, difficult, and dangerous. Her responsibility, however, is not only to the community but also, in nursing matters, to the hospital. She is usually in touch with other hospital departments before the sun breaks the horizon, and it has been said with some truth that the personality of the hospital is that of the casualty sister. Should she, too, not be given the benefit of similar training?-I am, etc.,

E. P. Abson, Secretary,

Casualty Surgeons Association,

Isle of Wight. 